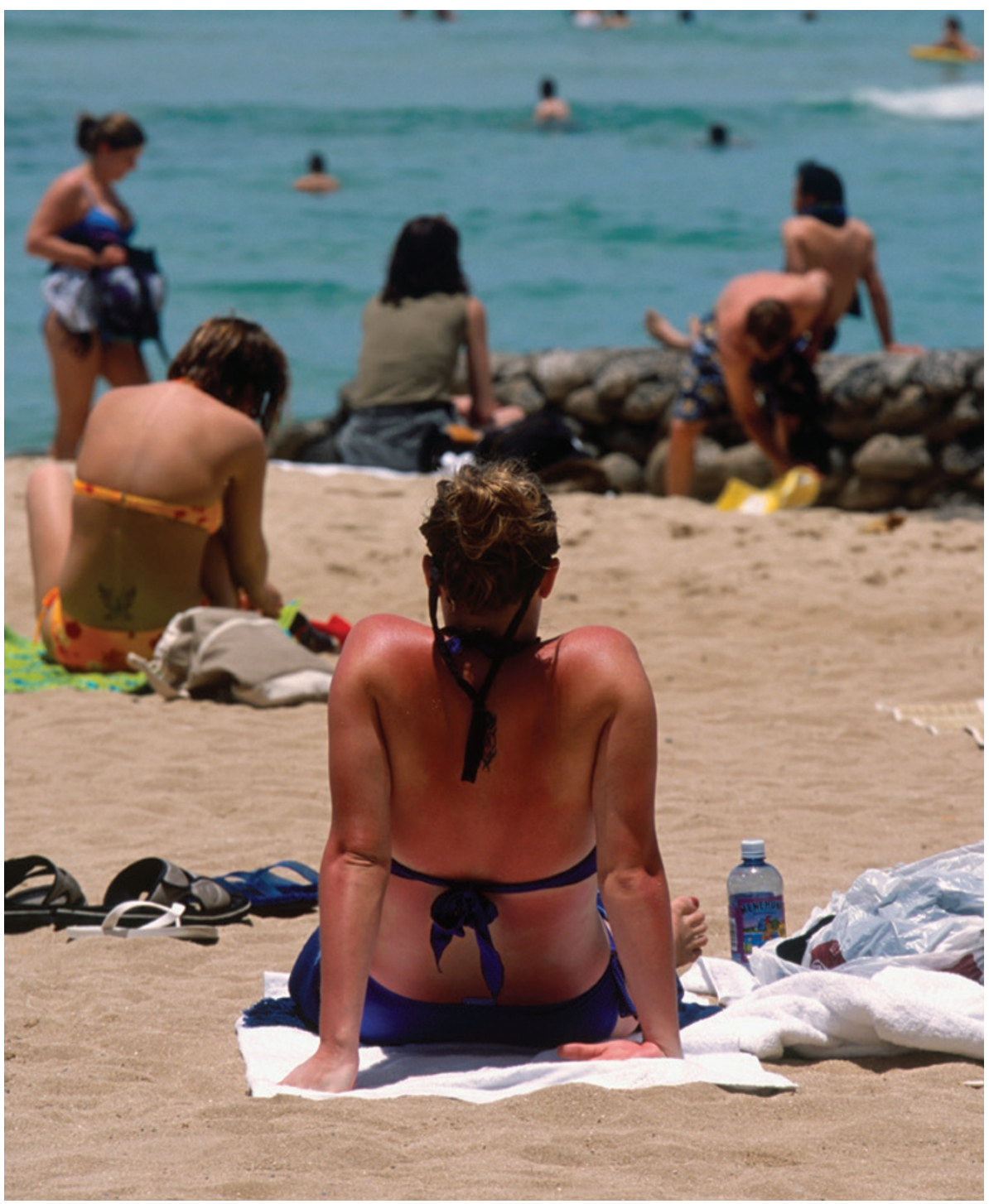

The rewards of sunbathing can be immediate but the melanoma risk may seem distant and intangible.

PREVENTION

\title{
Lessons from a sunburnt country
}

\section{Countries that can't persuade people to stay safe in the sun could learn from Australia, melanoma capital of the world.}

\section{BY ZOË CORBYN}

$\mathrm{B}$ efore she leaves home in San Francisco, California, Jennifer Schaefer dons long sleeves and a big hat she calls her "personal umbrella". With her fair skin, red hair, memories of bad childhood sunburn, and a family history of skin cancer, Schaefer is painfully aware of the dangers of exposure to ultraviolet radiation, which accounts for the vast majority of skin cancers.

So she finds it mind-boggling how few people bother with sun safety, with most preferring sun worship to sun protection. "In our culture, it's almost funny to be too sun protected," she says, highlighting the way her friends tease her when she dons her bathing suit - a protective 'rash guard' top and knee-length board shorts.
"We're slowly starting to become aware of the long-term effects of the sun, but it's like global warming - people are not going to make serious changes until they feel a direct impact."

That impact has helped push Australians, $\frac{}{z}$ who are famous for sun loving, into changing their behaviour. With its high solar ultraviolet levels and predominantly fair-skinned population, Australia has the highest rate of skin cancer in the world. But after decades of increase, the melanoma rate began to plateau in the mid $1990 \mathrm{~s}^{1}$. The incidence of melanoma among young people is now falling ${ }^{1,2}$, as national surveys show that most Australians - more than $70 \%$ of adults and $55 \%$ of adolescents - no longer prefer $\operatorname{atan}^{3}$.

\section{SLIP! SLOP! SLAP!}

One reason for the change is that Australia essentially hit saturation point, says Adèle Green, a cancer epidemiologist at the QIMR Berghofer Medical Research Institute in Brisbane. Melanoma was so common that most people knew someone who had suffered from it, so the need to act was obvious. There has also been an ongoing skin-cancer awareness campaign to educate the public $c^{4,5}$ that started in the early 1980s with the well-known 'Slip! Slop! Slap!' television commercial, in which an animated seagull told Australians how to stay safe in the sun. The SunSmart programme today combines mass media campaigns and intensive work with schools, workplaces, local government, health professionals, parents and sports groups. Operating under the control of charities called cancer councils, with funding from state governments, the SunSmart programme has made Australia a world leader in preventing skin cancer.

When Green was growing up, annual sunburn for children was "just a fact of life", she says. As a teenager, she and her friends cooked themselves "like bacon and eggs" in suntan oil. Melanoma rates are still increasing among older people ${ }^{1}$ because damage done early in life can trigger malignancy decades later. But Green believes there has been a national change in mindset. "Generations born since 'Slip! Slop! Slap!' have known nothing but a culture imbued with sun protection messages," she says.

Many other countries struggling to get their populations to make sun protection part of daily life would love a little of Australia's magic. In July 2014, the US surgeon general issued a 'call to action' (go.nature.com/zy27zl) asking all sectors of society to come together to reduce exposure to ultraviolet radiation. "One of the reasons we put this report out is to do what Australia did years ago," says Boris Lushniak, acting US surgeon general. The report details increasing rates of skin cancer and says most people are not doing enough to protect themselves from the sun. One in three adults has had sunburn in the past year, it says. It also points to the high use of sunbeds by young white women, with nearly one in three 
I engaging in the practice each year (see 'Banning indoor tanning').

"We have increased knowledge but there is not a lot of evidence for changing behaviour," says Joel Hillhouse, a psychologist who directs the Skin Cancer Prevention Laboratory at East Tennessee State University in Johnson City. So why aren't people in the United States and elsewhere heeding the messages? What lessons can be learned from Australia?

One powerful obstacle to people protecting their skin properly is our culture's view that a tan is attractive and healthy. "The social perception that tans are beautiful is a barrier we still as a society haven't overcome," says Eleni Linos, a dermatologist who studies skin-cancer prevention at the University of California, San Francisco. Perpetuating this notion, says Hillhouse, is a multibillion-dollar tanning industry.

Then there is the nuisance factor: protecting skin requires steps such as remembering a hat or applying sunscreen that can seem more trouble than they're worth ${ }^{6}$. The risk-reward balance works against sun protection in many people's minds, says Carolyn Heckman, a psychologist specializing in skin-cancer prevention at the Fox Chase Cancer Center in Philadelphia, Pennsylvania. The risk of skin cancer can seem minor, distant and intangible. By contrast, tanning can provide instant gratification.

But there is nothing immutable about people's affinity for the sun. Indeed, until the early 1900 s, pallor was popular in Europe and North America because it indicated an upper-class lifestyle and an occu-

"We have increased knowledge but there's not a lot of evidence for changing behaviour." pation that did not entail outdoor labour (this idea still prevails in many Asian countries). Then in the 1920s doctors began prescribing sunbathing as medication for ailments such as tuberculosis. Many people credit French style icon Coco Chanel with making the tan chic by bronzing herself on a yacht in the Mediterranean. By the 1960s the bikini had arrived, and tanning beds further increased the population's exposure to ultraviolet radiation.

But our love of the sun is more than just cultural. Our biology makes it hard to stay away too. Frequent sunbathers and indoor tanners can exhibit symptoms of addiction. Mice exposed to a daily dose of ultraviolet radiation develop higher levels of the feelgood hormone $\beta$-endorphin within a week, and exhibit classic symptoms of withdrawal when the endorphin rush is blocked ${ }^{7}$. This effect may explain why it feels good to go out on a sunny day, says David Fisher, director of melanoma research at Harvard University in Cambridge, Massachusetts, who led the mouse study. He believes it could be a relic of our evolution, dating back to

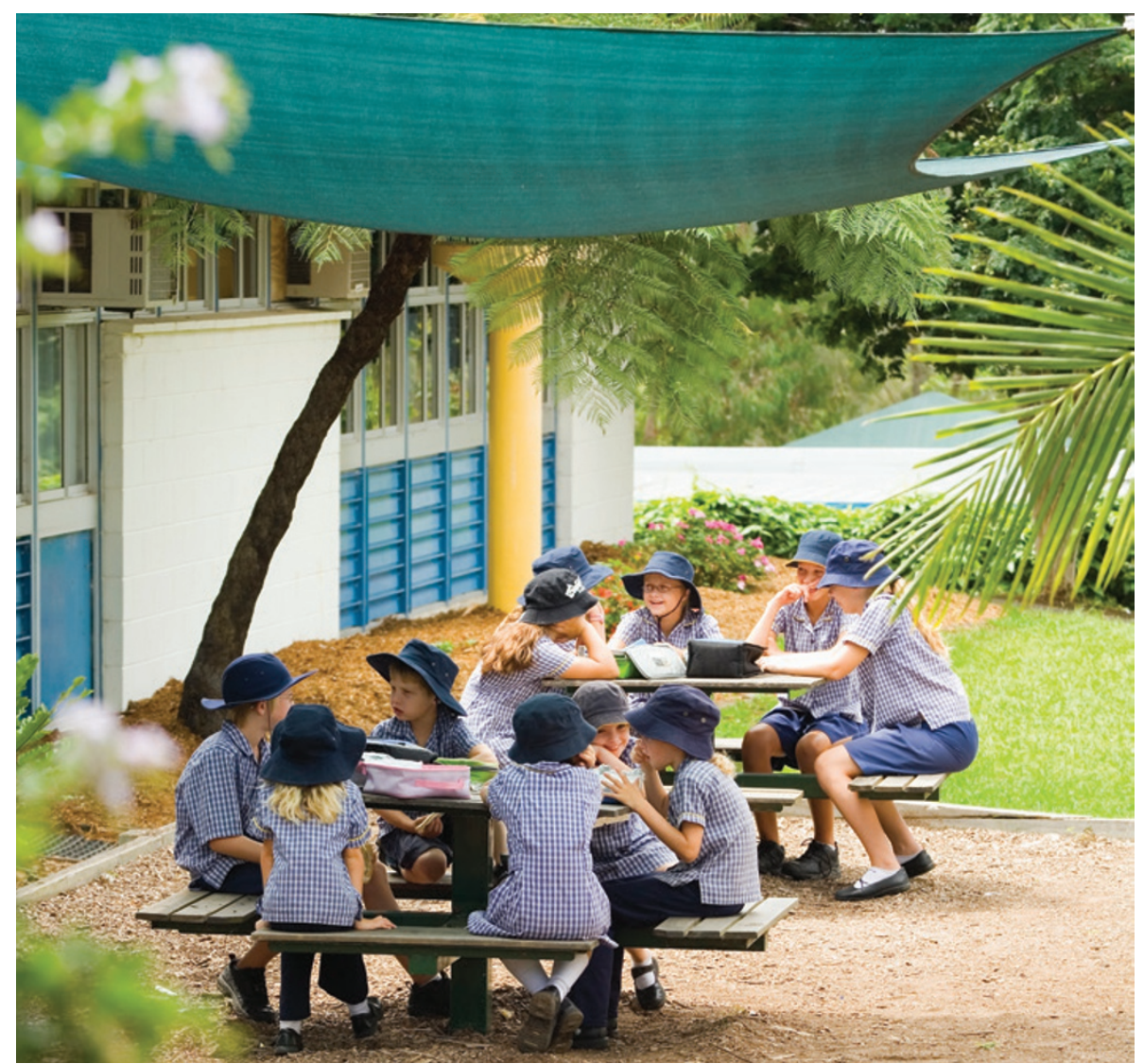

Australian primary schools typically provide plenty of shade and encourage children to wear sun hats.

when being outside in the sun could have conferred health benefits and even saved lives by triggering the skin to synthesize the vitamin D required for strong bones.

"Per exposure, the power of the euphoric effect is pretty small," Fisher says. "But if people have just a modestly increased propensity to seek ultraviolet radiation, over a population of millions you have an increase in skin cancer." Recognizing the addictive effect, he believes, could aid public-health efforts. For example, he argues that regulatory agencies should take a tougher stance with young people on sunbeds because of the possibility of dependence. And public-health messages could be enhanced by explaining to people that our physiology means we have less control than we think. "It might allow people to step back and look more objectively at their behaviour," he says.

\section{MIXED MESSAGES}

Inconsistent public-health messages may also be hampering behavioural change. In 2012, DeAnn Lazovich, a cancer epidemiologist at the University of Minnesota in Minneapolis, compared the recommendations to prevent skin cancer from four US health bodies ${ }^{8}$. They sometimes had different messages and ranked the order of protective actions differently. "Anyone trying to figure out what they ought to do might be a little bit confused," she says.

Linos is worried by a general overemphasis on sunscreen, the most common protective measure people take. Her research shows that sunscreen users get sunburn more frequently than those who seek shade or wear protective clothing ${ }^{9}$. Although people may be more likely to apply sunscreen before prolonged exposure to the sun, she acknowledges, they often fail to apply it thickly enough to be effective. It can also lull users into a false sense of security. "People feel they can stay out longer," she explains.

Contradictory information about vitamin $\mathrm{D}$ has added to the confusion, says Martin Weinstock, a dermatologist and community-health researcher at Brown University in Providence, Rhode Island. There have been suggestions that vitamin D can help prevent everything from cancer to diabetes (although a 2010 Institute of Medicine report found insufficient evidence for any beneficial effect beyond bone health), and the tanning industry has seized on this, says Weinstock. So the public hears warnings about the need for sun protection juxtaposed with messages about the benefits of vitamin D. "It doesn't take much contradictory messaging to really screw up the whole enterprise," Weinstock says.

Different countries resolve this conflict in different ways. The United States has encouraged people to protect themselves from ultraviolet radiation and to get any additional vitamin D they need from supplements. But Australia advises people that they may need to seek sun exposure to ensure adequate vitamin D levels, which they can do safely by going 
outdoors without sun protection at times of day when ultraviolet levels are low. This 'do no harm' approach is balanced and realistic, says Craig Sinclair, who heads prevention at Cancer Council Victoria in Australia. But Weinstock disagrees, arguing that there is no guaranteed safe level of ultraviolet exposure. "A little bit of sun is not going to do you a lot of harm, but it will do you a little bit of harm," he says.

What's more, public-health messages haven't always been well designed for the demographic groups they are intended to target. Hillhouse has studied what motivates young women who use sunbeds to change their behaviour, and it has little to do with their health ${ }^{10}$. "A young person's view of skin cancer is that it is just so far off," he says. It's better to focus messages on something they care deeply about: their appearance. For young women, Hillhouse advocates stressing the link between ultraviolet exposure and wrinkles and, importantly, suggesting safe alternatives to achieve a socially desirable appearance, such as exercise. "Public health tends to take an almost religious view you just tell people what is going to make them healthier and they will do it," he says. But that approach is flawed, Hillhouse explains. "Psychology says we need to work with the person in ways that matter to them."

\section{AUTOMATIC FOR THE PEOPLE}

One lesson Australia can teach other countries, says Sinclair, is that prevention campaigns require sustained resources. "Every time we take our foot off the pedal and reduce our investment, we get a regression in behaviour," he says.

Indeed, funding for prevention campaigns in the United States has only ever been sporadic - there has never been a serious national campaign. "The resources we have put into stopping smoking, drunk driving or AIDS have never been put into skin cancer," says Hillhouse. In the United Kingdom, where rising skin-cancer rates are thought to be driven by the popularity of cheap overseas travel and indoor tanning ${ }^{1,11}$, the charity Cancer Research UK has run a prevention campaign for the past decade. It is based on Australia's SunSmart brand but the investment has only been "very small" in comparison, says Sinclair. Yet prevention provides value for money by reducing expensive treatment costs: every Aus $\$ 1$ spent on SunSmart in Australia delivers a net saving of $\$ 2.30$ (ref. 12).

Another important lesson - also apparent from anti-smoking campaigns - is that an educational component alone is not enough. Mass media campaigns targeted at changing individuals' behaviour have to be backed by policies and legislation. "Just personal choice is not going to do it," says Green. Australian primary schools, for example, have adopted 'no hat, play in the shade' policies, and also have commitments to provide sufficient shade in school grounds. Sunscreen is available in

\section{BANNING INDOOR TANNING \\ The campaign against sunbeds}

It is hard to overstate Clare Oliver's role in Australia's campaign against sunbeds. She was a 26-year-old journalist who died of melanoma in late 2007, but she devoted the last month of her life to publicizing the dangers of indoor tanning, which she blamed for her melanoma. The media frenzy that followed her appearance on television led the state of Victoria to become the first in Australia to announce it would ban people younger than 18 from using commercial tanning beds. Other states soon followed, but what Oliver started didn't stop there - at the end of 2014, all Australian states will ban commercial indoor tanning completely. Australia will be the second country after Brazil, which took action in 2009, to have imposed such a ban. The World Health Organization classified sunbeds as carcinogenic in 2009.

Many European countries have also legislated to ban access to sunbeds for minors, including the United Kingdom
(Scotland in 2009, England and Wales in 2011, and Northern Ireland in 2012). The ban couldn't come soon enough. It is well established that melanoma incidence is lower in the north of England than in the sunnier south, but the high prevalence of indoor tanning among young women in the north of England is thought to be one reason why they buck the trend ${ }^{11}$.

Eleven US states, led by California in 2011, have prohibited indoor tanning for those under the age of 18 (others have weaker restrictions and 10 states have none at all). In May 2014, the US Food and Drug Administration reclassified tanning beds from low risk (class I) to moderate risk (class II), and it now requires manufacturers to include a warning advising against their use for people younger than 18. "Society makes the decisions," says Boris Lushniak, the acting US surgeon general. "But this is needless exposure to ultraviolet radiation, a known carcinogen." z.c. classrooms, and sun protection is taught to children of all ages. By contrast, many US primary schools ban hats on the school grounds (partly to discourage cliques) and only allow sunscreen to be dispensed by a school nurse. "We would like those students to be allowed to use proper sun protection," says Lushniak.

Australia has succeeded, says Linos, because it has coupled its educational campaign with efforts to make it easy to use sun protection. "If you make it automatically part of daily life it is much easier," she says. It takes less effort to stay in the shade where there is plenty available, to pay attention to the ultraviolet index when it is part of the weather forecast, and to persuade children to wear hats when they are used to wearing one at school.

Meanwhile there is some cause for optimism outside Australia. Attitudes have started to change. Hillhouse says he has unpublished US data showing that a mild, rather than dark or moderate, tan is now preferred. In his study, participants sought "just enough tan to take away the pale look". And analysis of American women's fashion magazines over several decades shows that models are not as tanned as they used to be ${ }^{13}$.

A 2013 study shows that, in addition to Australia, a handful of countries - notably New Zealand, Canada, Israel, Norway, the Czech Republic (for women) and the United States (for white men) - have melanoma rates that are declining or stabilizing among young people ${ }^{1}$."Very slowly we seem to be turning the tide," says Green.

Researchers say the US surgeon general's call to action will need to be backed by funding to have the greatest effect, but they hail it as a step in the right direction. Sun safety "has been elevated to a public-health priority now", says Lazovich. "It gives groups something to get behind," adds Weinstock.

Back in San Francisco, Jennifer Schaefer is doing her best to educate the next generation. Her eldest daughter automatically puts on a hat to go outside. "Habits really start in childhood — it is like brushing your teeth," she says.

Zoë Corbyn is a freelance journalist based in San Francisco, California.

1. Erdmann, F. et al. Int. J. Cancer 132, 385-400 (2013).

2. lannacone, M. R., Youlden, D. R., Baade, P. D., Aitken, J. F. \& Green, A. C. Int. J. Cancer http://dx.doi.org/10.1002/ijc.28956 (16 May 2014).

3. Volkov, A., Dobbinson, S., Wakefield, M. \& Slevin, T. Aust. N. Z. J. Public Health 37, 63-69 (2013).

4. Sinclair, C. \& Foley, P. Br. J. Dermatol. 161(suppl. 3), 116-123 (2009).

5. Iannacone, M. R. \& Green, A. C. Melanoma Mgmt 1, 75-84 (2014)

6. Goulart, J. M. \& Wang, S. Q. Photochem. Photobiol. Sci. 9, 432-438 (2010).

7. Fell, G. L., Robinson, K. C., Mao, J., Woolf, C. J. \& Fisher, D. E. Cell 157, 1527-1534 (2014).

8. Lazovich, D., Choi, K. \& Vogel, R. I. Cancer Epidemiol. Biomark. Prev. 21, 1893-1901 (2012).

9. Linos, E. et al. Cancer Causes Control 22, 1067-1071 (2011).

10. Hillhouse, J., Turrisi, R., Stapleton, J. \& Robinson, J. Cancer 113, 3257-3266 (2008).

11. Wallingford, S. C., Alston, R. D., Birch, J. M. \& Green, A. C. Br. J. Dermatol. 169, 880-888 (2013).

12.Shih, S. T., Carter, R., Sinclair, C., Mihalopoulos, C. \& Vos, T. Prev. Med. 49, 449-453 (2009).

13.George, P. M., Kuskowski, M. \& Schmidt, C. J. Am. Acad. Dermatol. 34, 424-428 (1996). 